Beygelzimer Y. Kulagin R. Estrin Y.

Davydenko O. Pylypenko A.

\title{
MICROMANUFACTURING BY SEVERE PLASTIC DEFORMATION
}

We are talking here about employing Severe Plastic Deformation (SPD) processes to fabricate materials for structures whose characteristic dimensions range from $10 \mu \mathrm{m}$ to $10 \mathrm{~mm}$, say.

SPD technology has been around for some 20 years. A defining feature these techniques have in common is the use of giant shear deformation in conjunction with a gigantic, gigapascalrange, hydrostatic pressure. Despite the extreme cumulative equivalent strains imparted to the workpiece in these processes, its dimensions remain practically unchanged, which distinguishes the SPD techniques from traditional metal forming operations [1,2].

The consequences for materials processed by SPD in terms of their mechanical properties are remarkable, as their initial grain structure is reduced in a spectacular way - down to deep submicron scale, and in some cases to nanoscale [3, 4]. Not only are such techniques suitable for providing bulk materials with an ultrafine-grained (UFG) structure, but they can also be efficient for consolidation and 'cold sintering' of metal powders [5], solid-state modification of polymers [6, 7], recycling of machining chips $[8,9]$, and other engineering applications.

The last ten years have seen increased efforts to transfer the substantial knowledge accumulated through laboratory scale SPD research to industry $[10,11]$. Commonly the success of such transfer is seen to hinge on the adaptation of SPD technologies to 'real production'. What is meant is upscaling of the dimensions of the processed billets, improvement of productivity, and reduction of manufacturing cost. It can easily be demonstrated that satisfying all these requirements is a formidable and challenging task, however.

First, SPD studies have shown that, for all other conditions being the same, the growing dimensions of the workpieces lead to an increase in the smallest attainable average grain size $[12,13]$. A possible explanation for this phenomenon, which deteriorates the microstructure and the properties of materials upon upscaling, was given in $[12,14,15]$. As with all metal forming processes, these problems are compounded by greater non-uniformity of the material's characteristics throughout the workpiece.

If the characteristic dimensions of a billet are increased by a factor of $\mathrm{k}$, the power of plastic deformation (i.e. the mechanical work per unit time) becomes $\sim \mathrm{k}^{3}$ times greater, while the power associated with work against the frictional forces is increases by a factor of $\sim \mathrm{k}^{2}$. Considering that the attendant stresses associated with SPD processing are high compared with conventional metal forming due to lower temperatures and higher pressures involved, upscaling of SPD requires the use of much more powerful and robust equipment.

From the viewpoint of classical metal forming, the dies used for SPD usually have fairly unfavourable geometry, which gives rise to non-uniform distribution of stresses in the tooling. The reason is that the dies are designed to direct the metal flux in such a way as to produce high flow rates within narrow regions, such as e.g. zones of intensive shear under equal-channel angular pressing or twist extrusion. This means that the longevity of the gear employed in 'real production' can only be provided by specialty materials, which are rather costly. Besides, SPD processing is prone to material waste, caused particularly by unwanted shape distortions imparted to the billets. 
The mentioned factors limit the competitiveness of SPD processes in the 'real production' if it is understood in terms of mass production of articles with large dimensions.

The situation changes to the better radically if SPD processing is applied to small scale engineering. Then the problems of upscaling disappear. In the 'real production' of miniaturised items the workpiece sizes and the achievable batch volumes are easily manageable with the currently available equipment. For instance, for a characteristic size 1 of a part, the mass of the material of density required for producing $\mathrm{N}$ parts would be. For a batch of, say, one billion parts with $1=1 \mathrm{~mm}$ the required weight of steel would be $7,800 \mathrm{~kg}$, while for $1=0.1 \mathrm{~mm}$ it would be as small as $7.8 \mathrm{~kg}$.

For a given fraction of the material cost in the overall cost of the product, the expenditures for the material in small scale engineering is much higher than in the manufacturing of large size parts. This compensates for the capital expenditures for expensive tooling. The material waste in this case does not matter too much either.

The gravity of the possible drawbacks of SPD thus becomes less severe, while their advantages - and this is the crux of small scale engineering - are indisputable. Let us demonstrate that.

It is well known that a low scatter in a batch of products can only be ensured if the size of a representative material volume is at least an order of magnitude smaller than the product size. At the same time, the size of a representative material volume should be at least an order of magnitude greater than the average grain size (if we are talking a rather general case of a polycrystalline material). For an article with a typical size of, say, $0.1 \mathrm{~mm}$ this means that the material it is made from needs to have a submicron grain structure. This is the grain size range that can routinely be attained by common SPD techniques.

A further requirement on the material is dictated by the need of stability of operation of a small-scale engineering structure, which is tantamount to the smallness of the scatter in the properties of the material. For that, a high degree of uniformity of chemical composition and microstructure over a length scale commensurate with the size of the product is necessary. Again, SPD technologies can deliver the required level of a material's homogeneity.

Finally, an important forte of SPD processes is their ability to create entirely new materials that cannot be manufactured by other methods. What is meant by that is the possibility to enable material transport within the workpiece and mechanically induced solid-state chemical reactions induced by large plastic deformations under high pressure.

The publication in 1935 of P. Bridgman's first results on high pressure torsion [16] (an SPD method that is currently taking central stage in SPD research), prompted headlines of the following kind in popular press: 'Harvard Scientists Produce Alloy By Pressure Method', 'New Technique Uses Pressure To Form Alloys', 'Scientists Make Miniature Earthquake' and the like. In one of his interviews P. Bridgman said prophetically: "The new 'high pressure' method might eventually result in means of making useful alloys from metals which cannot be combined into alloys by the conventional method of fusion at high temperature" [17]. In developing the high pressure torsion technique P. Bridgman was inspired by a stunning multitude of phenomena in nature that can be associated with shear deformation under high pressure. These include the formation of various geological structures, earthquakes, and the metamorphism that gives rise to a rich gamut of minerals and ores. In recent years, the work initiated by P. Bridgman has motivated active research into the mass transport and physico-chemical phenomena that occur under SPD conditions. Our publication [18] provides an overview of research on the use of these processes to create new hybrid materials, which we refer to as SPD-induced synthesis.

Figure 1 illustrates some phenomena occurring under SPD, which promote SPD-induced synthesis. 


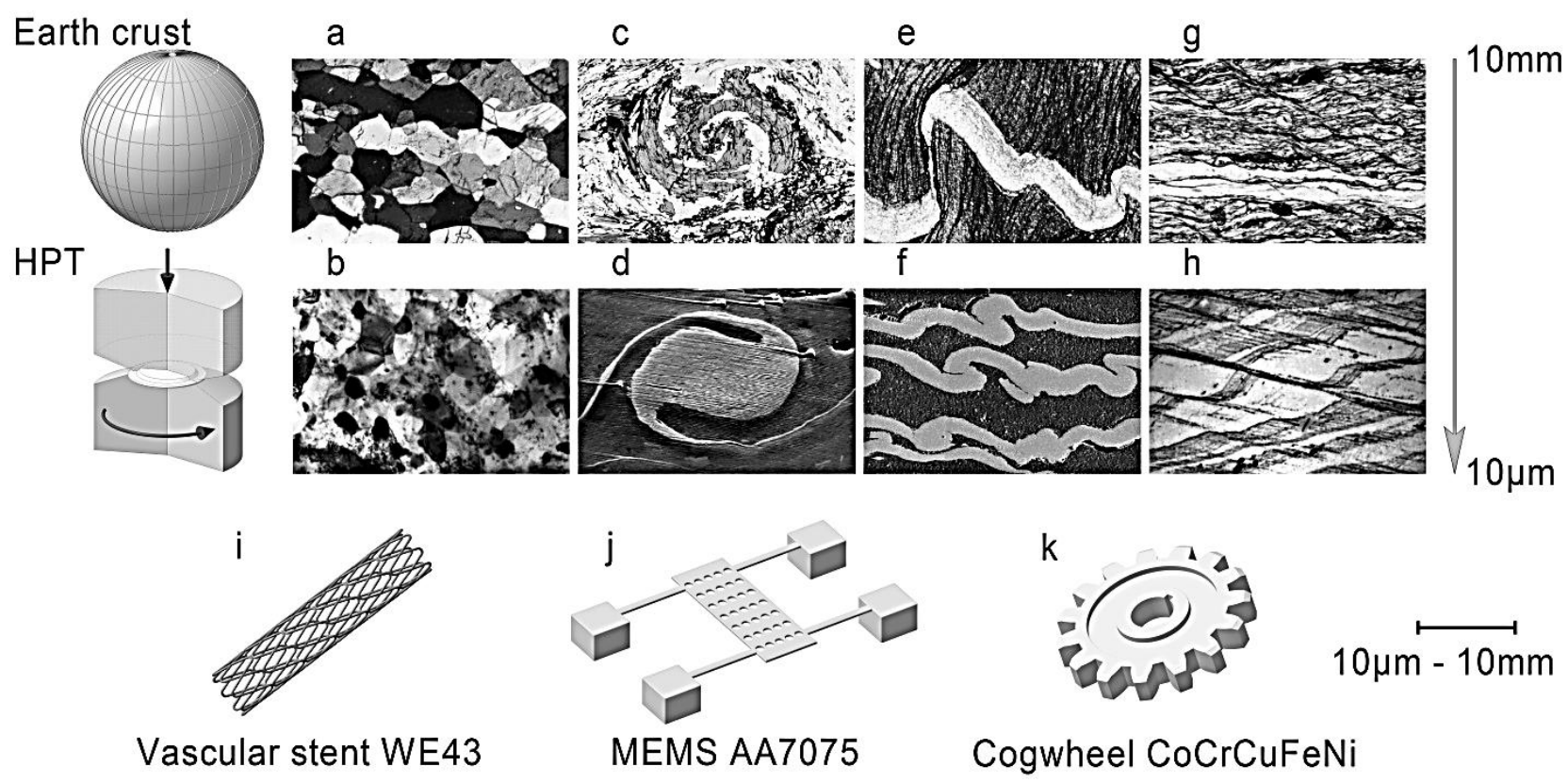

Fig. 1. Pattern formation in nature and SPD-induced materials synthesis. The pictures demonstrate analogies between geological formations in the Earth's crust and microstructures produced by HPT (middle row). The lower row displays examples of articles which can be produced by SPD-assisted microfabrication:

(a) and (b) - Fragmentation (a - Polygonal fabric of recrystallized scapolite grains; $b-\mathrm{Cu}-$ 07\% Cr-09\%Hf alloy); (c) and (d) - Vortex Formation (c - Si garnet in micaschist; $\mathrm{d}-\mathrm{Cu} / \mathrm{Al}$ multilayer), (e) and (f) - Folding (e - Crenulation cleavage; $\mathrm{f}-\mathrm{Ni} / \mathrm{Al}$ multilayer), (g) and (h) - Shear Banding ( $\mathrm{g}$ - Shear band cleavage in micaschist; $\mathrm{h}$ - aluminium alloy 1050). (Image $\mathrm{b}$ - courtesy Dr. E. Lukyanova; images d, f - courtesy Dr. A. Mazilkin.)

(i), (j), and (k): examples of miniature articles which can potentially be manufactured from SPD-processed materials: a bioresorbable vascular stent from magnesium alloy WE43, a sensitive elastic element for MEMS from aluminium alloy 7075, and a cogwheel from a superstrong highentropy alloy, respectively.

In the small-scale engineering we envisage, articles made from new materials would be produced by microforming and microcutting. The viability of SPD processing at a millimetre scale has been demonstrated in earlier work [19]. Examples from the wire manufacturing at 1 mil scale [20] suggest that fabrication of the tooling necessary for micro-SPD would not pose a technical problem either.

The small size of SPD equipment required for manufacturing of miniaturised parts makes it possible to accommodate it virtually on an office desktop or a laboratory benchtop. A manufacturing facility of that kind can easily serve as an R\&D laboratory as well. We believe that such combined manufacturing/research facilities will be extremely efficient in answering the industry's demands for small scale engineering. It is hoped that through the present communication we can attract the attention of researchers and engineers to this avenue and possibly divert the efforts at industrial applications of SPD processing to the more promising area of microfabrication.

\section{CONCLUSIONS}

The small size of SPD equipment required for manufacturing of miniaturised parts makes it possible to accommodate it virtually on an office desktop or a laboratory benchtop. A manufacturing facility of that kind can easily serve as an R\&D laboratory as well.

The combined manufacturing/research facilities will be extremely efficient in answering the industry's demands for small scale engineering. 


\section{REFERENCES}

1. Valiev R.Z., Korznikov A.V., Mulyukov R.R., Structure and properties of ultrafine-grained materials produced by severe plastic deformation. Materials Science and Engineering.1993, 168, 2, pp. 141-148.

2. Valiev R.Z., Estrin Y., Horita Z., Langdon T.G, Zehetbauer M.J., Zhu Y.T. Producing bulk ultrafinegrained materials by severe plastic deformation. JOM. 2006, 58, pp. 33-39.

3. Valiev R.Z., Estrin Y., Horita Z., Langdon T.G., Zehetbauer M.J., Zhu Y.T. Producing bulk ultrafinegrained materials by severe plastic deformation: ten years later. JOM. 2016, 68, pp. 1216-1226.

4. Estrin Y., Vinogradov A. Extreme grain refinement by severe plastic deformation: A wealth of challenging science. Acta Materialia. 2013, 61, pp. 782-817.

5. Bachmaier A., Pippan R. Generation of metallic nanocomposites by severe plastic deformation. Int. Mater. Rev. 2013, 58, pp. 41-62.

6. Enikolopian N.S. Superfast polymerization under high pressure and plastic flow. Macromolecular Chemistry. 1984,185, pp. 1371-1381.

7. Beloshenko V., Beygelzimer Y., Voznyak Y. Solid-State Extrusion, Encyclopedia of Polymer Sciences. John Wiley \& Sons. 2015. https://doi: 10.1002/0471440264.pst343.pub2

8. Beygelzimer Y., Kulagin R., Estrin Y., Toth L.S., Kim H.S., Latypov M.I. Twist extrusion as a potent tool for obtaining advanced engineering materials: a review. Advanced Engineering Materials. 2017, 19, 8. DOI: https://doi.org/10.1002/adem.201600873

9. Lapovok R., Qi Y., Ng H.P., Maier V., Estrin Y. Multicomponent materials from machining chips compacted by equal-channel angular pressing. Journal of Materials Science. 2014, 49, pp. 1193-1204.

10. Lowe T.C. Metals and alloys nanostructured by severe plastic deformation: commercialization pathways. JOM. 2006, 58, 28. https://doi.org/10.1007/s11837-006-0212-8

11. Herold F., Schmidt A., Frint Ph., Götze1 U., Wagner M. Franz-Xaver. Technical-economic evaluation of severe plastic deformation processing technologies-methodology and use case of lever-arm-shaped aircraft lightweight components. The International Journal of Advanced Manufacturing Technology. 2018, 94, pp. 3619-3632. DOI: https://doi.org/10.1007/s00170-017-0921-x

12. Utyashev F.Z., Raab G.I., Effect of the deformation zone on the structure refinement in metals. The Physics of Metals and Metallography. 2007, 104, 6, pp. 582-594.

13. Beygelzimer Y., Varyukhin V., Synkov S., Orlov D. Useful properties of twist extrusion. Materials Science and Engineering A. 2009, 503, 1-2, pp. 14-17.

14. Utyashev F.Z., Raab G.I., The model of structure refinement in metals at large deformations and factors effecting grain size. Rev. Adv. Mater. Sci. 2006, 11, pp. 137-151.

15. Beygelzimer Y., Lavrinenko N. Perfect plasticity of metals under simple shear as the result of percolation transition on grain boundaries. arXiv:1206.5055v1 [cond-mat.mtrl-sci]. 2012.

16. Bridgman P.W., Effects of high shearing stress combined with high hydrostatic pressure. Physical Review. 1935, 48, pp. 825-847.

17. Kaveh Edalati, Zenji Horita A review on high-pressure torsion (HPT) from 1935 to1988. Materials Science\&Engineering A. 2016, 652, pp. 325-352.

18. Beygelzimer Y., Estrin Y., Kulagin R., Synthesis of Hybrid Materials by Severe Plastic Deformation: A New Paradigm of SPD Processing, Advanced Engineering Materials. 2015, 17, 12, pp. 1853-1861.

19. Estrin Y., Rabkin E., Hellmig R.J., Kazakevich M., Zi A. New Applications of the SPD Concept: $\mu$ SPD. / Eds. Zhu Y.T., Varyukhin V. Nanostructured materials by high-pressure severe plastic deformation. nato science series (II: Mathematics, Physics and Chemistry), Springer, Dordrecht. 2006, v. 212.

20. Micro and Precision Manufacturing (Engineering Materials) Ed. Kapil Gupta, Springer International Publishing AG, Cham, Switzerland. 2017, 195 p.

Beygelzimer Y. - Professor, Principal ResearcherDIPhENASU; E-mail: yanbeygel@gmail.com;

Kulagin R. - Ph. D., Researcher INT, KIT;

Estrin Y. - Professor FAAHonorary Professorial Fellow, CAHM, MU;

Davydenko O. - Ph. D., Senior Researcher DIPhENASU;

Pylypenko A. - Ph. D., Junior Researcher DIPhENASU.

DIPhENASU - Donetsk Institute for Physics and Engineering named after O. O. Galkin, National Academy of Sciences of Ukraine, Kyiv;

INT, KIT - Institute of Nanotechnology, Karlsruhe Institute of Technology, Germany;

CAHM, MU- Centre for Advanced Hybrid Materials, Monash University, Australia. 